\title{
SISTEMA REGIONAL DE INOVAÇÃO: ESTUDO DAS REGIÕES BRASILEIRAS*
}

\author{
Giovana F. Rossi Casali*
}

\section{Orlando Monteiro da Silva ${ }^{* * *}$}

\author{
Fátima M. A. Carvalho ${ }^{* * *}$
}

\begin{abstract}
RESUMO Este trabalho analisou o processo de formação regional do Brasil, os desequilíbrios existentes entre as regiões e as perspectivas futuras. Teve como proposta básica analisar o possível processo de convergência de renda das regiões brasileiras, utilizando o conceito de gap tecnológico. Segundo esse conceito, os desequilíbrios regionais são o resultado de diferentes taxas de desenvolvimento econômico, que, por sua vez, resultam de diferentes níveis de desenvolvimento tecnológico, os quais, por fim, são consequências de condições históricas, sociais e culturais específicas de cada região. Dessa forma, pressupôs-se a existência de relação positiva entre nível de desenvolvimento tecnológico, dependência tecnológica, dependência econômica, nível de desenvolvimento econômico e convergência de renda. Os resultados mostram que, em relação à possibilidade de as regiões e os estados menos desenvolvidos realizarem o catching up com aqueles mais desenvolvidos, as variáveis que representam tanto a geração quanto a apropriação de novas tecnologias são significativas e diretamente relacionadas com o produto. Dessa forma, pode-se afirmar que o $c a$ tching up seria possível caso houvesse um maior investimento no processo de desenvolvimento e apropriação de novas tecnologias por parte dos governos regionais.
\end{abstract}

\footnotetext{
* Artigo enviado em 14 de julho de 2009 e aprovado em 31 de outubro de 2010.

** Professor adjunto do Departamento de Economia da Universidade Federal de Viçosa, e-mail: grossi@ufv.br

*** Professor associado do Departamento de Economia da Universidade Federal de Viçosa, e-mail: odsilva@ufv.br

**** Professora aposentada do Departamento de Economia Rural da Universidade Federal de Viçosa. Coordenadora do Programa Rede Estadual de C\&T para Inovação Agroindustrial - Sectes/MG, e-mail: fmac@ufv.br
} 
Palavras-chave: economia regional; economia brasileira; desenvolvimento tecnológico; Schumpeter

Código JEL: R11; O18

\section{REGIONAL INNOVATION SYSTEM: A STUDY OF BRAZILIAN REGIONS}

ABSTRACT This research developed an analysis on the regional imbalances at the Brazilian economy, the historic formation of the regions and perspectives. As a result of the distinctive courses followed by each region, an economical concentration process occurs in the Southeast. In this sense, this study intended to analyze the possible process of the Brazilian regional formation, using the concept of technological gap. The result show that, in relation to the possibilities of the regions and states that are less developed to accomplish the catching up with those that are more developed, the variables that represent generation as does the appropriation of new technologies were found to be significant and directly related to the product. Therefore, it can be affirmed that catching up would be possible if there was a higher investment en the process of development and appropriation of new technologies by the regional governments.

Key words: regional economy; Brazil's economy; technological development; Schumpeter 


\section{INTRODUÇÃO}

O final do século XX foi um período de grande crescimento e desenvolvimento para a maior parte das economias mundiais. Entretanto, deixou para o Brasil dois grandes desafios a serem vencidos. Por um lado, tem-se o fato de ser um país integrado em uma economia mundialmente desequilibrada, em que coexistem grandes países desenvolvidos, outros em processo de desenvolvimento e, ainda, países de baixo nível de desenvolvimento socioeconômico. Mesmo no grupo dos países em desenvolvimento podem ser constatadas marcantes diferenças entre economias de industrialização recente, na Ásia, e economias latino-americanas, de baixo grau de industrialização.

Por outro lado, o Brasil compõe-se de regiões que, a exemplo da economia mundial, também apresentam grandes disparidades entre si, fazendo com que seja um país que enfrenta duplo desequilíbrio socioeconômico externo e interno. Em síntese, é um país em desenvolvimento, inserido em uma economia mundial, composta por países em diferentes níveis de desenvolvimento, que, ainda, apresenta, internamente, regiões igualmente desequilibradas.

Por meio de uma análise histórica da economia brasileira, verifica-se que, já no período da colonização, o Brasil apresentava regiões com diferentes níveis de desenvolvimento econômico. Iniciando-se no ciclo da cana-de-açúcar, no século XVII, passando pelas economias mineradora e cafeeira e, posteriormente, pelo processo de industrialização, já no século XX, pode-se identificar claramente um padrão de concentração de produção e renda na região Sudeste, com tendência a um aprofundamento cada vez maior. Enquanto nessa região desenvolviam-se infraestrutura urbana, canais de transporte, pontos de comércio, atividade financeira, as demais regiões permaneciam estagnadas. No Nordeste, predominavam as grandes propriedades rurais autossuficientes; no Norte, tinha lugar predominantemente a atividade extrativa, localizada de forma esparsa em toda a extensão da floresta amazônica; no Sul, estabeleciam-se pequenos núcleos de povoamento, sem grande expressão econômica; e, por fim, o Centro-Oeste, que permanecia praticamente desabitado (Furtado, 2002).

Como resultado desses diferentes caminhos seguidos pelas cinco regiões brasileiras, ocorre um processo de concentração econômica no Sudeste, que 
é, ao final do século XX, a região mais rica do país. Entretanto, nas últimas décadas, mais especificamente a partir dos anos 1970, iniciam-se esforços, principalmente do governo federal, com o objetivo de desenvolver as demais regiões. A partir desse período, a tendência de concentração regional existente no Brasil deixa de ser um consenso, iniciando-se, então, um debate sobre uma provável tendência de convergência de renda.

Apresentando como ponto de partida a teoria neoschumpeteriana, o presente trabalho pretende mostrar que diferentes taxas de desenvolvimento econômico podem ser explicadas pela existência de diferentes taxas de desenvolvimento tecnológico e diferentes níveis de desenvolvimento sociais, culturais e históricos. Desse modo, podem-se explicar a existência de disparidades regionais ou os desequilíbrios regionais por meio dos diversos níveis de desenvolvimento tecnológico apresentados por cada região, ou adaptando o conceito de sistema nacional de inovação para o conceito de sistema regional de inovação. Diferentes sistemas regionais de inovação resultam em diferentes níveis de desenvolvimento tecnológico e econômico, reproduzindo, assim, os desequilíbrios regionais existentes na economia brasileira.

Segundo Saviotti (2005), existe um conjunto de fatores que influenciam o desenvolvimento e a localização das inovações. O sucesso das inovações e a sua taxa de difusão são função do desenvolvimento histórico, social e institucional, ou seja, do sistema de inovação de uma dada região. Diferentes regiões, com diferentes sistemas de inovação, diferentes histórias, sociedades e culturas, resultam em diferentes níveis de desenvolvimento econômico. Nesse sentido, o sistema de inovação de um dado país ou região é um fator fundamental da sua capacidade de criar e de adotar inovações e, portanto, de gerar um processo de desenvolvimento tecnológico e econômico.

Assim, para entender o desenvolvimento de uma dada região, faz-se necessário estudar todos os elementos que a compõem, focalizando as instituições e interações existentes e as que deveriam existir. Em um processo de desenvolvimento sustentável, a criação de um ambiente institucional que estimule a capacitação técnica, inovação, difusão e incorporação de novas tecnologias tem importância fundamental, assim como o estímulo das características qualitativas e quantitativas de todo o ambiente e o relacionamento entre pesquisa básica e aplicada, pesquisadores e empresários, inovação, difusão e incorporação de novas tecnologias. Diferentes instituições e 
inter-relações entre o quadro institucional e o setor produtivo resultam em distintos esforços de inovações e níveis de desenvolvimento em diferentes regiões. Nesse sentido, define-se sistema nacional de inovação como um arranjo institucional entre os agentes de um dado país - firmas, universidades, institutos de pesquisa, instituições financeiras, governo - que impulsiona o desenvolvimento tecnológico deste.

Assim, a proposta principal deste trabalho foi verificar a existência de relação direta entre desenvolvimento econômico e desenvolvimento tecnológico. O ponto de partida do modelo utilizado (Fagerberg, 1988) é a existência de níveis diferenciados de capacitações tecnológicas entre países (regiões), as quais determinam um desnível tecnológico, gap de produtividade, entre estes, diferenciando-os entre países (regiões) adiantados ou desenvolvidos e países (regiões) atrasados ou em desenvolvimento ou subdesenvolvidos. O nível de capacitação de cada país (região) é dependente tanto da sua capacidade de inovação e difusão quanto da sua capacidade de imitar e absorver a inovação introduzida pelos outros países (regiões).

Para que o gap se reduza, é necessário que o esforço inovação/difusão/ imitação do país (região) atrasado seja muito superior ao do país (região) adiantado. Além disso, tem-se como fator fundamental do processo de desenvolvimento econômico a capacidade de reter e apropriar a inovação, mediante a difusão da tecnologia, tanto já incorporada no processo produtivo ou no produto, como também na forma de know-how (Fagerberg, 1988). Dessa forma, neste trabalho, pretendeu-se verificar a possibilidade de realização do catching up. Dadas as condições regionais atuais, intencionou-se verificar se as regiões mais atrasadas serão capazes de superar as adversidades e alcançar o nível de desenvolvimento econômico das regiões mais desenvolvidas.

\section{O PROCESSO DE FORMAÇÃO ECONÔMICA DAS REGIÕES DO BRASIL}

Em uma perspectiva ampla, segundo Furtado (2002), pode-se definir o sistema econômico do Brasil colonial como composto de dois subsistemas principais: a economia do açúcar na região Nordeste e a mineração no Sudeste do país. Articulados a esses dois subsistemas encontravam-se a pecuária nordestina, localizada no interior — sertão — da região, e a pecuária sulina, que se 
estendia de São Paulo ao Rio Grande do Sul. A principal ligação entre esses dois subsistemas era o rio São Francisco, que se encontrava no meio do caminho entre o Nordeste e o Centro-Sul. Além disso, havia pequenos subsistemas autônomos, que não se articulavam com o resto da economia. Na região Norte, localizavam-se os subsistemas da Amazônia, do Maranhão e do Pará, cuja principal atividade econômica era a extração florestal e que alcançou extraordinária importância relativa no final do século XIX. Na região Nordeste, destacava-se o subsistema da Bahia, com produção de cacau.

O subsistema da mineração teve lugar na região Sudeste do Brasil, principalmente no Estado de Minas Gerais, diferenciando-se do açúcar nordestino pela sua capacidade de indução econômica sobre outras atividades e regiões, especialmente sobre a pecuária sulina, a pecuária nordestina e o comércio paulista e fluminense - alimentos e vestuário. Essa era uma atividade essencialmente urbana, em que trabalhavam lado a lado a mão de obra escrava e a mão de obra livre, com geração de renda, demanda e, portanto, com a existência de um mercado interno embrionário. A principal herança dessa atividade foi a criação de uma infraestrutura de transportes, ligando Minas Gerais ao Nordeste, Rio de Janeiro, São Paulo e região Sul do país - um verdadeiro capital físico, que possibilitou o desenvolvimento da economia cafeeira no século XIX. O café desenvolveu-se na região Sudeste principalmente em razão da infraestrutura de transporte e comércio herdada do período minerador (Furtado, 2002).

No período da economia cafeeira, verifica-se uma importante modificação do equilíbrio demográfico e geoeconômico do país. Com o desenvolvimento das regiões cafeicultoras do Centro-Sul e a decadência do Nordeste, iniciam-se correntes demográficas fortes e constantes, partindo do sertão nordestino em direção ao Sudeste. Essa corrente será particularmente intensa depois da grande seca de 1877-1880, resultando no despovoamento do interior nordestino do Ceará até a Bahia (Prado Jr., 1987).

Em relação às atividades manufatureiras, verifica-se que, simultaneamente ao desenvolvimento da economia cafeeira, teve lugar um relativo progresso industrial, principalmente de manufaturas têxteis. A localização desses estabelecimentos se deu em função de dois fatores fundamentais: densidade demográfica e fontes de matéria-prima. Eles se concentraram nos Estados do Rio de Janeiro, Minas Gerais e em alguns centros do Nordeste 
— Pernambuco, Bahia e Maranhão - de densa população e elevada produção algodoeira, que era a principal matéria-prima. Nesse momento, São Paulo ainda figura em segundo plano no cenário econômico nacional. Assim, pode-se dizer que, inicialmente, as manufaturas encontravam-se amplamente disseminadas por todo o território nacional. No século XIX, verifica-se um processo de desenvolvimento manufatureiro-industrial simultâneo em quase todas as regiões do Brasil. Eram indústrias de bens de consumo não duráveis, de tecnologia simples, que não competiam com as importações externas. Essas primeiras indústrias não ultrapassavam o âmbito local ou sub-regional, onde possuíam vantagens em termos de economias de matérias-primas, transporte e comercialização (Castro, 1988).

Entretanto, no início do século XX, a indústria tendeu a concentrar-se na região Sudeste, ocorrendo o "grande salto quantitativo da indústria paulista". Segundo Furtado (2002), após o primeiro período de desenvolvimento, mais especificamente durante a Primeira Guerra Mundial, a indústria passou a concentrar-se regionalmente, resultando em crescente disparidade de renda inter-regional. Entre 1907 e 1919, enquanto a economia paulista apresentava elevadas taxas de crescimento, isso não ocorria nas demais regiões do país.

Na década de 1920, a indústria de São Paulo novamente experimenta um período de crescimento, tanto quantitativo quanto qualitativo, da sua estrutura produtiva, ao instalar um pequeno núcleo de indústrias de bens de capital e de insumos mais complexos, diversificando também, em certa medida, sua produção de bens de consumo. Ocorre, nessa região, um fenômeno de transbordamento do capital cafeeiro, que se divide em capital bancário, comercial e industrial. De acordo com Cano (2002), os próprios cafeicultores investiam parte de seus lucros em indústrias, seja direta ou indiretamente, por meio da intermediação financeira. Nesse período, além de São Paulo, apenas o Estado de Minas Gerais apresentou expressivas taxas de crescimento da sua economia.

No Estado de São Paulo, desenvolviam-se as indústrias tecnologicamente mais avançadas, que eram possíveis de serem instaladas no Brasil. Nas demais regiões, havia manufaturas e indústrias complementares ou voltadas para o próprio mercado regional. Eram indústrias de tecnologia simples e mão de obra não qualificada, de atividades complementares à atividade principal ou bens de consumo não duráveis, fábricas têxteis, por exemplo, 
destinadas ao mercado consumidor da região. No caso de produtos complementares, seu crescimento era, na maior parte das vezes, condicionado pelo comportamento da região central. Já em relação aos bens de consumo não duráveis, o mercado regional era protegido pelas dificuldades de transporte, que criavam barreiras à importação de produtos tanto do exterior quanto da região Sudeste. Eram, em geral, indústrias de pequeno e médio porte.

Em meados da década de 1950, o elemento dinâmico das regiões não industrializadas deixa de ser o mercado externo e passa a ser o mercado da região Sudeste (Cano, 2002). Esse período caracteriza-se pela intervenção do governo na criação de infraestrutura básica à industrialização e no incentivo à produção de bens de consumo duráveis, podendo-se citar as indústrias automotiva e de autopeças, química, naval, papel e celulose e material elétrico pesado.

Enquanto nas primeiras décadas do século XX o Brasil desenvolveu sua indústria e economia como uma resposta à crise da economia cafeeira, no pós-guerra a industrialização foi uma estratégia de desenvolvimento econômico planejada pelo governo. Essa nova fase da economia brasileira foi acompanhada de um movimento de urbanização, mas também de aprofundamento da concentração regional. O Brasil foi capaz de modernizar sua economia, desenvolver sua indústria, mas, ao fazer isso, gerou elevado grau de heterogeneidade econômica, regional, social e setorial. O aumento dos desequilíbrios regionais, entretanto, ocorreu como uma tendência natural de concentração da atividade econômica em torno da região central do país, concentração essa que foi consequência, primeiro, da escassez de capitais no período inicial do processo de crescimento industrial, e, depois, da política econômica governamental, que concentrava a renda na região Sudeste para permitir a industrialização (Tavares, 1983).

Em 1970, pode-se verificar que, como resultado do processo de desenvolvimento empreendido pela economia brasileira, no início dos anos 1970, o Estado de São Paulo era responsável por 58\% da produção industrial nacional e 39\% do PIB nacional (Siqueira e Siffert Filho, 2001). Como uma resposta a esse dado, o governo passa a focalizar a questão regional e, em uma tentativa de corrigir as disparidades existentes, formula uma série de medidas com vistas à redução seletiva na tendência de concentração regional, tendo início um movimento de descentralização da infraestrutura, com 
a construção de rodovias em direção às áreas fornecedores de matérias-primas, eletricidade, entre outros. Podem-se citar como exemplos a construção da rodovia Transamazônica, a expansão da fronteira agrícola no sentido Centro-Oeste e o direcionamento de recursos para as regiões Nordeste e Norte por meio de órgãos como Sudene e Sudam (Pimentel, 2004).

Segundo Castro (1988), estabelece-se nesse período uma divisão geográfica do trabalho entre o centro e algumas sub-regiões que assumem funções claramente definidas no organismo industrial brasileiro - Zona Metalúrgica, em Minas Gerais; Recôncavo Baiano; e Bacia Carbonífera, em Santa Catarina. Essas áreas se desenvolveram por meio de uma crescente elaboração e transformação de seus produtos básicos, da mineração para a metalurgia e desta para a produção de laminados, peças ou mesmo equipamentos; da extração do petróleo ao refino; e daí para a petroquímica.

Lemos et al. (2006), por sua vez, apontam os anos 1970 como o início do processo de reversão da polarização da região metropolitana de São Paulo, como o começo de um processo de dispersão espacial das atividades industriais. Andrade (1988) afirma que na década de 1970 as regiões menos desenvolvidas apresentaram taxas de crescimento superiores à mostrada pelo país. No período 1970/1975, pode-se afirmar o dinamismo das regiões Sul e Centro-Oeste, que apresentaram, respectivamente, taxas de crescimento da ordem de $12,86 \%$ e 13,24\%. Já a região Norte apresentou taxa de crescimento média anual de 14,34\% durante todo o período. Siqueira e Siffert Filho (2001) concluem que nos anos 1970 houve um processo de desconcentração econômica em favor das regiões Sul, Centro-Oeste e Norte.

Para os estudiosos da economia regional, os anos 1980 são objeto de controvérsia. Lemos et al. (2006) indicam uma diminuição na disparidade tecnológica durante toda a década, como consequência do processo de expulsão das atividades industriais do Estado de São Paulo, iniciado na década anterior. Entretanto, esse estado continua concentrando as indústrias tecnologicamente mais desenvolvidas, tendo-se como exemplo a metalmecânica. Rocha (1998), por sua vez, afirma que os primeiros anos da década de 1980 apresentam características de desigualdade máxima. O motivo principal é a diminuição da taxa de crescimento econômico da região Nordeste, em razão da ocorrência de um longo período de seca. Gonçalves (2005) identifica a existência de uma concentração tecnológica nas regiões Sudeste e Sul, de- 
finindo um "polígono industrial dinâmico" composto por Belo Horizonte, Uberlândia, Londrina, Porto Alegre, Florianópolis e São José dos Campos.

Diniz (1995), analisando as regiões brasileiras, conclui que, no período 1970/1985, a região Norte ampliou sua participação no produto industrial de $0,8 \%$ para $3,1 \%$. Essa ampliação deve-se aos incentivos fiscais concedidos pela Sudam e Suframa e pelo desempenho da Zona Franca de Manaus, com a produção de bens de consumo. A região Nordeste, por sua vez, embora apresente disparidades entre os seus estados, de forma geral, elevou sua participação na produção industrial de 5,7\% para 8,4\%, entre 1970 e 1990. Entretanto, o Estado da Bahia é o grande responsável por esses números, com os elevados investimentos públicos realizados no Polo Petroquímico de Camaçari. Já a região Centro-Oeste, embora sua produção industrial seja modesta, desenvolveu-se com a expansão da fronteira agrícola e do aproveitamento dos recursos minerais no Estado de Goiás. Por fim, a região Sul elevou sua participação no produto industrial de 12\%, em 1970, para 17\%, em 1990, dados o efeito da elevação da produção de grãos sobre as indústrias processadoras, o crescimento das indústrias de bens de capital e bens de consumo duráveis, no Rio Grande do Sul, e o crescimento da indústria de couros e calçados como resposta à demanda externa.

No entanto, o que se deve enfatizar é que, em 1980, a região Sudeste era responsável por mais de $60 \%$ do produto nacional, produzindo Cr\$ 7 bilhões dos cerca de Cr\$ 12 bilhões gerados pelo conjunto das atividades produtivas nacionais. Segundo Andrade (1988), a região Sudeste sempre apresentou, desde os anos 1950, o predomínio produtivo do país em qualquer setor; especialmente no setor secundário, $70 \%$ da produção concentram-se nessa região. Mais importante: pode-se perceber a ligação entre indicadores econômicos e tecnológicos. Na região Sudeste, região economicamente mais desenvolvida, concentram-se 70\% das despesas com desenvolvimento de tecnologias realizadas pelas empresas brasileiras. Somando-se as regiões Sudeste e Sul, esse percentual eleva-se para 90\% (Braga e Matesco, 1986).

Por fim, já nos anos 1990, a economia brasileira passou por importantes transformações, com a abertura econômica, o processo de privatização e a estabilidade monetária. Ocorrem alterações importantes na localização industrial, em razão da guerra fiscal empreendida pelos estados, com o objetivo de atrair grandes empresas para o seu território; da ação estatal, por meio 
de financiamentos via órgãos como BNDES e do estímulo à Zona Franca de Manaus; e, por fim, da intensificação da atividade mineradora na região Norte e do agronegócio no Centro-Oeste. Contudo, verifica-se a reconversão produtiva de algumas regiões do país: Diniz (1995) afirma que a participação de São Paulo na produção industrial do Brasil reduziu-se de 58\% para 49\% entre 1970 e 1990. Em síntese, no início do século XXI, pode-se ainda perceber a existência de concentração econômica entre as regiões brasileiras.

\section{TEORIA DE SISTEMA DE INOVAÇÃO}

\subsection{Sistema de inovação}

O conceito de sistema de inovação tem suas raízes no pensamento evolucionista, sendo seus principais pontos a importância central da inovação como fonte do crescimento da produtividade e do bem-estar material e o entendimento da inovação como um processo amplo, dinâmico, interdependente e complexo, envolvendo diversas instituições econômicas, sociais, culturais e históricas.

Entretanto, Fernandes (2005) encontra esse conceito em trabalhos bem mais antigos, identificando nos trabalhos de Friedrich List ideias semelhantes às encontradas no conceito de sistema de inovação. List criticou os economistas clássicos pela pouca atenção dada ao papel da ciência e tecnologia no desenvolvimento econômico. Ao estudar o desequilíbrio econômico entre Inglaterra e Alemanha, esse autor afirmava a necessidade da intervenção governamental no estímulo à educação e criação da infraestrutura e desenvolvimento da tecnologia, como forma de estimular o desenvolvimento industrial.

Por meio do sistema de inovação, busca-se compreender como ocorre o processo em que emergem as inovações tecnológicas, tanto em relação ao surgimento e à difusão dos elementos do conhecimento quanto em relação à transformação destes em novos produtos e processos de produção. A complexidade da dinâmica da inovação reside no fato de que ela não é assumida como um processo linear da pesquisa básica para a pesquisa aplicada e depois para o desenvolvimento e a implementação na produção. Envolve mecanismos de feedback e relações interativas entre ciência, tecnologia, apren- 
dizado, produção, política e demanda. Essa abordagem transcende a cadeia de causa e efeito que se inicia com P\&D e termina com o aumento da produtividade, mediada pela inovação e difusão. Pode até existir essa relação, mas o enfoque apenas nela não captura, em geral, os determinantes da inovação de maneira satisfatória. O sistema é dinâmico e seus elementos reforçam-se mutuamente, ou, ao contrário, combinam-se de tal modo que bloqueiam o processo de aprendizagem e inovação.

Dentre os grandes autores que desenvolveram e utilizam o conceito de sistema de inovação podem-se destacar Freeman, Nelson e Lundvall, desde o final dos anos 1970. Freeman et al. (1988) define sistemas de inovação como estruturas organizacionais e institucionais de suporte às mudanças tecnológicas, as quais têm caráter predominantemente nacional. Diferentes níveis de desenvolvimento nacional entre as nações devem-se aos seus diferentes sistemas de inovação. O conceito de sistemas de inovação refere-se a um amplo conjunto de atributos, que envolve arranjos sociais formais e informais, estruturas e instituições públicas e privadas, regras e convenções, em uma perspectiva histórica. Freeman ressalta, ainda, as características históricas, culturais e econômicas de cada país, as quais se refletem na organização interna das firmas e dos mercados produtor e consumidor, no papel do setor público e do setor financeiro.

Lundvall (1992) constrói duas definições de sistema de inovação. Em sentido estrito, refere-se à criação de organizações e instituições envolvidas diretamente na busca e exploração de inovações (departamentos de P\&D, universidades e institutos de pesquisa). Em sentido amplo, o conceito envolve aspectos da estrutura econômica e da configuração institucional que afetam (com intensidade variável) a aprendizagem, bem como a busca e a exploração (pelo sistema produtivo) de mercado e sistema financeiro, sem os quais a inovação não existe. Para Lundvall, o conceito de sistema de inovação possui uma conotação política e localizada do processo de inovação, em que a inovação depende fundamentalmente da articulação entre seus agentes e de fatores locacionais.

Segundo Mytelka (2000), sistema de inovação pode ser definido como uma rede de agentes econômicos, instituições socioculturais e políticas que condicionam o comportamento e a performance inovadora. Dessa forma, tem-se novo entendimento do conceito de inovação como um processo in- 
terativo, em que as empresas interagem umas com as outras e são apoiadas por instituições, organizações, $\mathrm{P} \& \mathrm{D}$, centros de inovação, universidades, bancos, que têm papel-chave na criação de novos produtos, novos processos e novas formas de organização.

Na perspectiva de sistema nacional de inovação, pode-se afirmar que os diferentes níveis de desenvolvimento econômico apresentados pelos diferentes países são consequência da forma como os fluxos de conhecimento são estruturados e da importância relativa dos diferentes tipos de instituições e encadeamentos dos respectivos sistemas de produção dentro de cada país. Isso ocorre porque cada país desenvolve seu próprio caminho tecnológico ou trajetória, o qual é determinado pelos padrões de acumulação passado e presente e pelos fatores institucionais específicos do país.

\subsection{Sistema regional de inovação}

Embora a perspectiva nacional tenha sido usualmente adotada, dependendo do objetivo do trabalho ou das características próprias do país em questão, pode-se trabalhar o conceito de sistema de inovação em um diferente nível de agregação. O principal argumento é que as diversas regiões que constituem um país possuem suas próprias características históricas, culturais, políticas e econômicas, diferenciando-se umas das outras e constituindo seus próprios sistemas de inovação. Embora as regiões façam parte de um mesmo país, e, portanto, têm uma história comum, cada região apresenta características que as distinguem das demais. Assim, foi desenvolvido, no início dos anos 1990 (Cooke, 2006), o conceito de sistema regional de inovação (SRI), levando à redescoberta da importância dos recursos regionais no estímulo do desenvolvimento tecnológico e econômico.

Em seu trabalho, Diniz (2001) cita vários autores que enfatizam essa ideia. Para Storper, o ambiente social e cultural tem papel crucial no desenvolvimento regional ou local por meio das interações entre as instituições. Putnam enfatiza a importância da sociedade civil e das tradições no desenvolvimento econômico regional. Saxenian estuda o papel da cultura no desenvolvimento do Vale do Silício. Amin e Thriff definem o conceito de robustez institucional para apontar a importância das relações entre as instituições culturais, sociais e políticas e a economia local ou regional. Hodgson enfatiza o peso da herança histórica como definidora de certos padrões 
de dependência, ou path dependence, no processo de desenvolvimento econômico regional.

Por sua vez, Asheim e Coenem (2004) sintetizam assim a importância da dimensão local:

- Presença de capital humano, interações entre firmas, escolas, universidades, centros de treinamento.

- Redes formais e informais entre vendedores e compradores para realização de negócios e troca de informações, por meio de encontros planejados ou casuais.

- Sinergias ou "excedente" inovativo, de cultura compartilhada.

- Existência legítima de poderes estratégicos de administração em áreas como educação, inovação e suporte empresarial. Para eles, o processo de aprendizagem é predominantemente interativo e socialmente imerso no ambiente institucional e cultural. A cooperação local passa a funcionar como determinante-chave na capacidade local de competição.

De acordo com Doloreux e Parto (2005), a inovação é espacialmente localizada, ocorrendo em um contexto histórico, institucional, político, social e econômico bem definido. Assim, ela está inserida em um contexto regional em que prevalecem regras, convenções e normas derivadas de fatores econômicos e socioculturais que diferenciam o desenvolvimento tecnológico e econômico de cada região.

Dessa forma, é necessário estudar todos os elementos que compõem uma região, focalizando as instituições e interações existentes, que deveriam ou não existir. Para que o desenvolvimento sustentável ocorra, é necessário criar um ambiente que estimule a capacitação técnica, inovação, difusão e incorporação de novas tecnologias, bem como estimular as características qualitativas e quantitativas de todo o ambiente e o relacionamento entre pesquisa básica e aplicada, pesquisadores e empresários, inovação, difusão e incorporação das novas tecnologias. Diferentes instituições e diferentes inter-relações entre o quadro institucional e o setor produtivo resultam em diferentes esforços de inovações e distintos níveis de desenvolvimento em diferentes regiões. Assim, o processo de catching up de uma região é possível por meio da construção das capacidades, da infraestrutura e da inter-relação entre estas, tendo em vista os processos de aprendizado dinâmicos, regionalmente localizados. 
No tocante à classificação dos sistemas regionais de inovação, podem-se distinguir dois diferentes tipos: empreendedor e institucional. $\mathrm{O}$ primeiro baseia-se no desenvolvimento do conhecimento, sendo orientado pela geração da ciência ou inovações/tecnologia. Por sua vez, o sistema regional de inovação institucional caracteriza-se por pertencer a uma estrutura industrial com grande fluxo de baixas e médias tecnologias.

\section{TEORIA NEOSCHUMPETERIANA}

\section{MODELO DE CATCHING UP E CRESCIMENTO ECONÔMICO}

Dentro do espírito da teoria neoschumpeteriana, a competição internacional pode ser vista como um processo contínuo de pesquisa por inovação que possa elevar, mesmo que temporariamente, os lucros do país. Assim, no período seguinte à introdução da inovação, tem-se uma posição de monopólio do país inovador, o que lhe confere taxas de lucros e salarial acima do normalmente verificado, observando-se elevação no gap tecnológico entre os países.

À medida que a tecnologia é transferida para outros países, ocorre a erosão da posição de monopólio em que o país se encontrava, levando à equalização das taxas de lucro e salariais e, consequentemente, a uma redução no gap tecnológico ou na dependência tecnológica. Para que o país inovador possa manter a liderança tecnológica e, consequentemente, manter elevadas relativamente as rendas dos fatores produtivos, é preciso também manter um processo contínuo e rápido de inovação tecnológica. Os países atrasados, por sua vez, para que possam diminuir o diferencial entre suas rendas e as dos países adiantados, têm de realizar investimentos maciços e contínuos em inovações, novas tecnologias de produto e processo, assim como na apropriação das inovações externas.

Entretanto, o grau de dependência tecnológica nos países em desenvolvimento depende não apenas da transferência de tecnologia, mas também da forma de sua apropriação, ou mais precisamente da falta de apropriação da tecnologia, por exemplo, learning by doing. Nesse sentido, faz-se crucial uma ação efetiva dentro desses países, fazendo da questão de importação de tecnologia não apenas um problema ligado às empresas privadas, mas ao desenvolvimento de um novo conceito de inovação e desenvolvimento, englobando os setores privado e público. 
O modelo do gap tecnológico do crescimento econômico desenvolvido por Fagerberg (1988) é, em essência, uma aplicação da teoria schumpeteriana do desenvolvimento capitalista, para uma economia mundial caracterizada pela competição entre os países (regiões). Parte-se do pressuposto de que a competição tecnológica entre firmas se reproduz em nível da competição entre países (regiões).

O ponto de partida é a existência de níveis diferenciados de capacitações tecnológicas entre regiões, as quais determinam um gap de produtividade entre elas, diferenciando-as entre regiões adiantadas ou desenvolvidas e regiões atrasadas. O nível de capacitação de cada região é função tanto da sua capacidade de inovação e difusão quanto da sua capacidade de imitar a inovação introduzida pelas outras regiões. Dessa forma, a taxa de crescimento de cada região é diretamente proporcional ao tamanho do seu gap, ou seja, inversamente proporcional ao seu nível de capacitação tecnológica. A possibilidade de a região realizar o catching up depende, diretamente, da capacidade inovativa e do esforço imitativo da região atrasada. Entretanto, depende também, inversamente, do esforço de inovação e difusão da região adiantada. Em outras palavras, pode-se dizer que a fronteira tecnológica é móvel, e as taxas de crescimento do produto e de elevação da produtividade das regiões atrasadas têm de ser suficientes para compensar o deslocamento da fronteira.

Para que o gap se reduza, é necessário que o esforço inovação/difusão/ imitação da região atrasada seja superior ao da região adiantada. Além disso, tem-se como fator fundamental a capacidade de reter e apropriar a inovação, por meio da difusão da tecnologia tanto já incorporada no processo produtivo ou produto como na forma de know-how. Em grande parte, o processo de estagnação prematuro das regiões atrasadas deve-se à não capacidade de endogeneização tecnológica. Assim, a questão do diferencial de crescimento deve ser mediatizada não só pela possibilidade de realização do catching up tecnológico, mas também pela capacidade de endogeneização do processo inovativo.

O modelo de Fagerberg (1988) tem como pressuposto básico que o nível de produção de um país (região) é função do nível de conhecimento criado internamente (inovação, tecnologia nacional), do nível de conhecimento nele difundido (imitação, difusão da tecnologia externa) e da sua capacidade de explorar os benefícios da tecnologia, seja ela interna ou externa - endogeneização do conhecimento. 
Assim, tem-se:

$$
Q=Z D^{\alpha} N^{\beta} C^{\tau}
$$

em que:

$Q=$ nível de produto do país (região);

$Z=$ constante;

$D=$ nível de apropriação da tecnologia externa — imitação das inovações externas;

$N=$ nível de criação de conhecimento — inovações realizadas internamente; e

$C=$ capacidade de explorar os benefícios da tecnologia, tanto interna quanto externa.

Diferenciando e dividindo por $Q$ e fazendo as letras minúsculas representarem taxas de crescimento, obtém-se:

$$
q=\alpha d+\beta n+\tau c
$$

Supondo, agora, que a contribuição da difusão da tecnologia disponível externamente para o crescimento econômico é uma função crescente da distância entre a tecnologia apropriada pelo país (região) e a tecnologia apropriada pelo país (região) que está na fronteira tecnológica, pode-se escrever:

$$
d=\mu-\mu\left(T-T_{f}\right)
$$

em que:

$\mu=$ coeficiente de conhecimento difundido;

$T=$ conhecimento apropriado pelo país (região) atrasado; e

$T_{f}=$ conhecimento apropriado pelo país (região) adiantado.

Substituindo (3) em (2), chega-se à equação final do modelo:

$$
q=\alpha \mu-\alpha \mu\left(T-T_{f}\right)+\beta n+\tau c
$$

em que:

$\alpha \mu-\alpha \mu\left(T-T_{f}\right)=$ fator de difusão da inovação externa - imitação;

$\beta n=$ fator de inovação interna; e 
$\tau c=$ capacidade de exploração dos benefícios da tecnologia interna e externa.

Por fim, Fagerberg sugere as seguintes proxies para seu modelo:

$$
q=\kappa+\alpha \mu \operatorname{Pr}+\beta_{1} P a t+\beta_{2} P d+\tau I
$$

em que:

$Q=$ taxa de crescimento do produto interno bruto (PIB);

$\operatorname{Pr}=$ relação entre o nível de produtividade do país (região) e o nível de produtividade do país (região) adiantado (definindo produtividade como o produto nacional dividido pelo número de trabalhadores do país (região));

$P a t=$ taxa de crescimento do número de patentes;

$P d=$ taxa de crescimento dos gastos com pesquisa e desenvolvimento (P\&D); e

$I=$ participação do investimento no produto nacional.

Quanto maior a importância das variáveis patente, $P \& D$, hiato da produtividade do trabalho e investimento na determinação da renda de uma região, maior a capacidade de ocorrência do catching up, ou, em outras palavras, de fechamento do gap, entre a região considerada e a região líder.

Dessa forma, a ocorrência de um processo de catching up depende da taxa de crescimento de cada região, o qual, por sua vez, depende diretamente da capacidade inovativa e do esforço imitativo do país atrasado e, por outro lado, depende inversamente do esforço de inovação e difusão do país adiantado.

Por sua vez, quanto maior a capacidade de crescimento de uma região menos desenvolvida em relação a uma região mais desenvolvida, verifica-se a existência de um processo de catching up. Ao contrário, quanto maior a capacidade de crescimento de uma região mais desenvolvida em relação a uma região menos desenvolvida, verifica-se uma elevação no gap entre essas regiões.

\section{METODOLOGIA}

Inicialmente, procedeu-se à estimativa de algumas estatísticas básicas (média, desvio-padrão, desvio médio e tendência linear), para as variáveis tanto regionais quanto estaduais utilizadas — produto, produto industrial, pro- 
duto da indústria de transformação, produtividade, produtividade industrial, patente, $P \& D$, energia elétrica industrial.

A seguir, foram construídos, por meio da estimação via dados em painel, três modelos de equações, tanto para as regiões quanto para os estados brasileiros. No primeiro, procurou-se estimar a possibilidade de catching up para a economia como um todo, tendo-se como variável dependente o nível do produto interno bruto da economia. Como variáveis independentes foram utilizados a produtividade do trabalho de todas as regiões e estados em relação àquela região ou estado mais desenvolvido, as atividades de $\mathrm{P} \& \mathrm{D}$ desenvolvidas em cada região e estado, o número de patentes registradas e o consumo de energia elétrica industrial também em cada região e estado.

No segundo modelo, considerou-se como variável dependente o produto da indústria (nível), e como variáveis independentes, as mesmas variáveis do primeiro modelo, com exceção da variável produtividade, que, neste caso, refere-se especificamente à produtividade relativa do setor industrial. Por sua vez, no terceiro modelo, assumiu-se como variável dependente o produto da indústria de transformação (nível), mantendo como variáveis independentes as mesmas do segundo modelo.

A variável produtividade relativa que é definida como produtividade do trabalho de uma dada região em relação à produtividade do trabalho da região mais desenvolvida é, neste modelo, utilizada como uma proxy da capacidade de absorção/imitação de tecnologias geradas por agentes econômicos externos à região. A maior produtividade do trabalho de uma dada região indica que ela tem incorporado novas tecnologias no processo produtivo. As variáveis patentes e P\&D são utilizadas como proxies da capacidade regional de desenvolvimento de novas tecnologias. A variável consumo de energia elétrica industrial é utilizada como uma proxy da formação bruta de capital fixo regional, na suposição de que, quanto maior for o investimento em máquinas e equipamentos, maior será o consumo de energia elétrica pelas indústrias. Os dados trabalhados foram obtidos no IPEA (Ipeadata) e Ministério da Ciência e Tecnologia (MCT).

Todas as equações foram estimadas utilizando-se, em primeiro lugar, dados regionais. Em seguida, as mesmas equações foram novamente estimadas com dados estaduais, para o período 1990 a 2005, período para o qual foi possível obter todos os dados necessários à estimação do modelo. 
Optou-se pela forma logarítmica, em que os coeficientes estimados são diretamente as elasticidades, ou seja, representam a resposta percentual da variável dependente às alterações em cada uma das variáveis explicativas.

Para definição dos melhores modelos a serem analisados, foram realizados os testes de Chow, LM de Breusch e Pagan, e Hausman. O teste de Chow teve como objetivo comparar o modelo de dados agrupados e o modelo de efeitos fixos; o LM destinou-se a comparar o modelo de dados agrupados e o modelo de coeficientes aleatórios; e o teste de Hausman possibilitou a escolha entre o modelo de coeficientes fixos e o modelo de coeficientes aleatórios.

Segundo esses testes, tanto para as regiões quanto para os estados, o modelo de coeficientes aleatórios foi mais indicado para as equações que têm como variável dependente o produto interno bruto, ou seja, para as equações que procuravam estimar a possibilidade de catching up para todos os setores da economia. $\mathrm{O}$ modelo de coeficientes fixos adequou-se melhor à estimativa de catching up para o setor industrial e, mais especificamente, para a indústria de transformação.

\section{ANÁLISE do CATCHING UP ENTRE REGIÕES E ESTADOS BRASILEIROS}

$\mathrm{Na}$ análise dos resultados, optou-se por apresentar ambos os modelos coeficientes fixos e aleatórios - para todos os três modelos de equações estimadas. A razão para tal procedimento deveu-se, por um lado, à teoria do modelo de dados em painel que afirma que, quando se trabalha com toda a população, o modelo de efeitos fixos conduz a melhores resultados. Entretanto, por outro lado, em algumas equações estimadas, o teste LM sinalizou ser o modelo de efeitos aleatórios o mais indicado. Dessa forma, procurou-se apresentar os dois modelos para atender à teoria, assim como ao teste LM.

A presença de heterocedasticidade (teste de Bartlet) e de autocorrelação (teste de Durbin-Watson) foi confirmada em todas as equações. Para correção, foram utilizadas as ponderações das variáveis por suas respectivas variâncias (heterocedasticidade) e o método de Cochrane-Orcutt (autocorrelação). Em algumas equações, o valor da estatística de Durbin-Watson, mesmo depois de efetuadas as correções, situou-se na zona de indeci- 
são, não permitindo, dessa forma, qualquer inferência sobre a presença ou não de autocorrelação.

Os valores das estatísticas descritivas para as regiões são apresentados na tabela 1.

Nas variáveis produto, produto industrial, produto da indústria de transformação, patente e $\mathrm{P} \& \mathrm{D}$, a região Sudeste apresenta os valores mais elevados entre todas as regiões brasileiras. Em seguida, observa-se a região Sul. Os valores da média indicam a existência de um grande desnível entre as regiões, enquanto os resultados para a tendência sugerem a persistência desse desequilíbrio, principalmente por os valores das demais regiões serem substancialmente inferiores. Entretanto, o fato de a região Sudeste apresentar também os maiores valores de desvio padrão mostra a existência de desigualdade inclusive dentro da própria região.

Os resultados das variáveis, produtividade, produtividade industrial e energia elétrica industrial não apresentam as disparidades observadas nas demais variáveis. O Sudeste continua apresentando os valores mais elevados para a média e tendência na produtividade e na energia elétrica industrial. O Nordeste aparece em seguida, ficando o Sul em terceiro lugar. Entretanto, como os valores são próximos, não se pode inferir a elevação das desigualdades regionais.

A variável produtividade industrial é a única na qual o Sudeste não apresenta os maiores valores, ficando em segundo lugar. A região que apresenta média e tendências mais elevadas é a região Norte. Atribui-se esse resultado à existência da Zona Franca de Manaus. O desvio padrão é o mesmo de todas as regiões.

Enquanto as variáveis patentes e P\&D indicam a existência de um processo de desenvolvimento de novas tecnologias, as variáveis produtividade e energia elétrica industrial sinalizam a utilização de novas tecnologias, e a variável produto mostra o resultado da organização do processo produtivo. Dessa forma, os resultados estatísticos obtidos mostram que as regiões $\mathrm{Su}$ deste e Sul são as mais desenvolvidas tecnologicamente, embora apresentem a mesma produtividade do trabalho das demais. Em termos de produto, esses resultados indicam uma tendência de perpetuação dos desequilíbrios entre as regiões brasileiras. 
Tabela 1: Estatísticas descritivas para as regiões do Brasil, média, desvio padrão e tendência

\begin{tabular}{|c|c|c|c|c|c|}
\hline Produto Total & Norte & Nordeste & Sudeste & Sul & Centro-Oeste \\
\hline Média & 4,73 & 13,13 & 57,75 & 17,93 & 6,45 \\
\hline Desvio Padrão & 4,79 & 13,29 & 56,58 & 17,79 & 7,55 \\
\hline Tendência & 4,72 & 12,78 & 59,23 & 18,02 & 5,24 \\
\hline Produto Industrial & Norte & Nordeste & Sudeste & Sul & Centro-Oeste \\
\hline Média & 4,52 & 11,54 & 61,77 & 19,09 & 3,08 \\
\hline Desvio Padrão & 5,10 & 12,34 & 59,99 & 18,74 & 3,84 \\
\hline Tendência & 3,94 & 10,34 & 63,77 & 19,69 & 2,25 \\
\hline $\begin{array}{l}\text { Produto da Indústria } \\
\text { Transformação }\end{array}$ & Norte & Nordeste & Sudeste & Sul & Centro-Oeste \\
\hline Média & 4,21 & 9,38 & 62,70 & 21,50 & 2,22 \\
\hline Desvio Padrão & 4,59 & 9,67 & 61,56 & 21,68 & 2,50 \\
\hline Tendência & 3,64 & 8,45 & 65,06 & 21,16 & 1,68 \\
\hline Produtividade & Norte & Nordeste & Sudeste & Sul & Centro-Oeste \\
\hline Média & 19,47 & 15,70 & 22,10 & 21,37 & 20,53 \\
\hline Desvio Padrão & 20,86 & 26,00 & 17,57 & 18,43 & 19,57 \\
\hline Tendência & 19,58 & 14,17 & 22,88 & 22,04 & 20,79 \\
\hline Produtividade Industrial & Norte & Nordeste & Sudeste & Sul & Centro-Oeste \\
\hline Média & 21,04 & 19,66 & 20,30 & 19,46 & 17,00 \\
\hline Desvio Padrão & 19,52 & 19,68 & 19,61 & 19,71 & 19,99 \\
\hline Tendência & 29,65 & 26,50 & 28,80 & 22,30 & 12,05 \\
\hline Patente & Norte & Nordeste & Sudeste & Sul & Centro-Oeste \\
\hline Média & 3,53 & 10,02 & 58,42 & 19,77 & 8,26 \\
\hline Desvio Padrão & 4,56 & 8,04 & 58,53 & 19,23 & 9,65 \\
\hline Tendência & 1,11 & 19,65 & 53,99 & 20,05 & 5,20 \\
\hline P\&D & Norte & Nordeste & Sudeste & Sul & Centro-Oeste \\
\hline Média & 0,64 & 8,87 & 70,27 & 15,19 & 5,02 \\
\hline Desvio Padrão & 0,45 & 8,39 & 69,89 & 15,83 & 5,44 \\
\hline Tendência & 0,67 & 8,92 & 70,29 & 15,12 & 5,00 \\
\hline Energia Elétrica Industrial & Norte & Nordeste & Sudeste & Sul & Centro-Oeste \\
\hline Média & 5,97 & 16,70 & 61,13 & 13,88 & 2,32 \\
\hline Desvio Padrão & 7,57 & 18,50 & 56,02 & 15,13 & 2,78 \\
\hline Tendência & 5,60 & 16,88 & 64,48 & 11,34 & 1,71 \\
\hline
\end{tabular}

Fonte: Cálculos do autor.

Entretanto, para que se possa inferir a ocorrência de um processo de $\mathrm{ca}$ tching up entre as regiões e estados brasileiros, faz-se necessário estudar o peso de cada uma dessas variáveis na determinação do produto, do produto industrial e do produto da indústria de transformação.

\subsection{Estimação do modelo de efeitos fixos para as regiões brasileiras}

Em primeiro lugar, na análise da possibilidade de catching up para as regiões brasileiras pelo modelo de efeitos fixos (tabela 2), a variável de maior 
influência no produto regional é a produtividade relativa do trabalho, com uma elasticidade de curto prazo igual a 0,62, significando que, para cada $1 \%$ de variação na produtividade relativa, resulta uma variação de mesmo sentido de $0,62 \%$ no produto regional. Assim, uma parcela significativa das variações no produto nacional pode ser explicada por variações na produtividade, ou seja, pela capacidade de cada região absorver novas tecnologias. A variável patente também se mostrou igualmente significativa, embora tenha menor influência sobre o produto regional $(0,7)$. Por outro lado, a variável $\mathrm{P} \& \mathrm{D}$, embora significativa, apresentou sinal contrário à expectativa, indicando que uma elevação nos esforços de P\&D levaria a uma pequena redução no nível do produto. Embora esse resultado possa indicar a presença de uma alta colinearidade entre as variáveis patente e P\&D, um exame da matriz de correlação não indicou a existência de um elevado grau de associação entre essas variáveis. Por fim, a variável consumo de energia elétrica industrial não se mostrou significativamente importante.

Esses resultados mostram que, em relação ao produto total regional, a variável com maior capacidade para influenciar um possível catching up das regiões menos desenvolvidas em relação àquelas mais desenvolvidas é o hiato da produtividade do trabalho. Assim, uma região será tanto mais capaz de alcançar as demais regiões quanto maior a sua capacidade de imitação de novas tecnologias.

Além da produtividade do trabalho, a variável patente mostrou-se importante para a realização do catching up regional, o que mostra a capacidade de criação interna de tecnologia como um importante fator de desenvolvimento econômico e que pode levar as regiões a distinguirem-se umas das outras. A variável $\mathrm{P} \& \mathrm{D}$, por outro lado, que também é utilizada para representar o desenvolvimento tecnológico de cada região, não se mostrou significativa, o que pode ser explicado pelo fato de a patente representar o final do processo de geração de novas tecnologias, ou seja, o registro das inovações realizadas, prontas para serem utilizadas, enquanto P\&D representa o processo em si de criação de tecnologias, que, muitas vezes podem acabar sem serem sequer patenteadas. Em outras palavras, o processo de $P \& D$ muitas vezes pode não se transformar em inovações que possam ser utilizadas pelos setores produtivos. Dessa forma, esse processo por si só, sem a certeza de se estar gerando uma inovação passível de ser utilizada, não faria grande diferença no processo de catching up regional. 
Tabela 2: Catching up, regiões brasileiras - dados anuais em painel 1990 a 2005, modelo de efeitos fixos

\begin{tabular}{lccc}
\hline & Produto Total & Indústria & Indústria de Transformação \\
\hline Constante & $17,60^{*}$ & $15,66^{*}$ & $14,73^{*}$ \\
\hline P\&D & $(188,39)$ & $(40,18)$ & $(38,51)$ \\
\hline Patente & $(-5,29)$ & $0,02^{*}$ & $0,02^{* * *}$ \\
\hline Produtividade & $0,07^{*}$ & $(11,73)$ & $(1,13)$ \\
\hline & $(9,55)$ & $0,11^{*}$ & $0,08^{*}$ \\
\hline Energia Elétrica Industrial & $0,62^{*}$ & $(6,85)$ & $(5,02)$ \\
\hline & $(11,73)$ & $0,41^{*}$ & $0,59 *$ \\
\hline Número de observações & $0,01 * * * *$ & $(3,55)$ & $0,12^{*}$ \\
\hline R $^{2}$ & $(0,99)$ & $0,07^{*}$ & $(5,95)$ \\
\hline Teste Chow & 175 & $(3,30)$ & 40 \\
\hline Teste LM & 0,99 & 40 & 0,99 \\
\hline Teste Hausman & $3.803,63$ & 0,99 & 776,25 \\
\hline DW & 0,0000000145 & 0,000000229 & 0,000000044 \\
\hline Teste Bartlet & 32,73 & 15,43 & 16,03 \\
\hline Os & 1,84 & 1,92 & 1,57 \\
\hline
\end{tabular}

Os valores entre parênteses referem-se à estatística $t$ de student.

*Nível de significância 1\%**Nível de significância 5\%***Nível de significância 10\%****Não significativo.

Fonte: Cálculos do autor.

Por fim, a variável consumo de energia elétrica industrial não apresentou o comportamento esperado segundo a teoria do catching up, o que pode ser explicado pelo fato de o setor industrial ser apenas uma parte do produto total. Assim, o consumo de energia elétrica pelas indústrias por si só não teria influência significativa em todo o setor produtivo.

Isso significa que, para estimular o desenvolvimento regional, para elevar produto e renda, o principal fator a ser considerado é a capacidade de imitação de novas tecnologias, expresso por meio do hiato da produtividade do trabalho, seguido pelo esforço interno de geração de novas tecnologias (patentes). Isso revela que, se as regiões menos desenvolvidas investirem tanto na imitação de tecnologias externas, que elevem a produtividade do trabalho, quanto no desenvolvimento de novas tecnologias, patentes, a uma taxa relativamente maior que as regiões mais desenvolvidas, apresentarão uma taxa de crescimento do produto relativamente maior e, portanto, maior probabilidade de realizar o catching up. Entretanto, o contrário também é verdadeiro. No caso de as regiões mais desenvolvidas investirem a uma taxa 
relativamente maior na imitação e na criação interna, elas apresentarão maiores taxas de crescimento do produto, e, portanto, o gap entre as regiões tenderá a elevar-se.

A equação que tem como variável dependente o produto industrial regional apresentou todos os resultados significativos $(\mathrm{P} \& \mathrm{D}$, patente, produtividade e consumo de energia elétrica industrial), com sinais esperados. Aqui, também, a variável que exerce maior influência sobre o produto industrial regional é o hiato da produtividade do trabalho, seguida das variáveis patente, consumo de energia elétrica industrial e P\&D.

A variável consumo de energia elétrica industrial, utilizada como proxy para a formação bruta de capital fixo regional, utilizada sob o pressuposto de que novas máquinas utilizam uma quantidade maior de energia, mostrou-se significativa nesse caso. Isso indica que a tecnologia incorporada em novas máquinas também é importante para o desenvolvimento do setor industrial e, portanto, das regiões onde estão as indústrias.

Patente foi o terceiro mais importante fator em um processo de crescimento do setor industrial regional, ou seja, a capacidade de geração de novas tecnologias. Nessa regressão, a variável P\&D também se mostrou significativa, podendo igualmente contribuir para o catching up.

Dessa forma, a exemplo do produto regional, em relação à possibilidade de catching up industrial, as principais variáveis consideradas são a capacidade regional de imitação de novas tecnologias no setor industrial, a capacidade regional de difusão e, por fim, a capacidade de criação de novas tecnologias que estimulem o desenvolvimento das indústrias. Assim, pode-se afirmar ser o processo regional de geração de novas tecnologias, quantificado por meio de dados de $\mathrm{P} \& \mathrm{D}$ e patentes, importante fator no crescimento do produto regional, exercendo, portanto, importante papel em um processo de catching up regional, desde que essas regiões desenvolvam novas tecnologias a uma taxa superior à apresentada pelas regiões mais desenvolvidas.

Para a equação do produto regional da indústria de transformação, encontrou-se que a variável $P \& D$ não foi significativa, enquanto as demais o foram no nível de $1 \%$. Acredita-se que tal resultado tenha ocorrido pelo fato de essa variável representar os gastos de $\mathrm{P} \& \mathrm{D}$ totais realizados na região, pois não existiam dados específicos para a indústria de transformação. Novamente, a variável com maior influência sobre o produto regional da indús- 
tria de transformação foi a produtividade relativa do trabalho, encontrando-se em segundo lugar o consumo de energia elétrica industrial e, em seguida, patentes.

Essa terceira equação, que, dentro do setor industrial regional, destaca a indústria de transformação, confirma o fato de a produtividade da mão de obra ser, em relação às regiões brasileiras, o fator mais importante para $o$ crescimento da renda e produto e, portanto, em um processo de catching up, seguido pelo consumo de energia elétrica industrial. Assim, reafirma-se a importância da imitação de tecnologias externas no crescimento do produto da indústria de transformação regional.

A variável patente, representando o processo de geração interna de novas tecnologias, também se mostrou um importante fator, de novo enfatizando a importância de um processo de inovação regional. Entretanto, a variável P\&D mostrou-se não significativa, indicando haver, dentro da indústria de transformação, a exemplo do produto total, um descompasso do processo de desenvolvimento tecnológico e sua utilização pelos setores produtivos.

Assim, para a indústria de transformação, as principais variáveis foram o hiato da produtividade do trabalho (a capacidade regional de imitação de novas tecnologias no setor industrial), o consumo de energia elétrica (que indica a capacidade de difusão de tecnologias por todo o setor) e as patentes, (a capacidade de criação de novas tecnologias que estimulem o desenvolvimento das indústrias de transformação).

\subsection{Estimação do modelo de efeitos aleatórios para as regiões brasileiras}

Os resultados encontrados no modelo de efeitos aleatórios são apresentados na tabela 3. Embora, teoricamente, o modelo de efeitos fixos seja a melhor especificação, pois neste trabalho considera-se toda a população, ou seja, todas as regiões e estados brasileiros, o teste de Hausman indicou o modelo de efeitos aleatórios como o melhor para estimar as regressões. Desta forma, optou-se por apresentar os dois modelos.

Na primeira equação, em que a variável dependente é o produto regional, verificam-se as principais distinções entre os modelos de efeito fixo e variável, sendo a variável consumo de energia elétrica industrial não significativa. Além disso, enquanto no modelo de efeitos fixos o sinal da variável P\&D era 
negativo, no modelo de efeitos aleatórios todos os sinais estão de acordo com o esperado. Entretanto, novamente acredita-se que o sinal negativo da variável P\&D nas regressões que têm como variável dependente o produto e o produto regional deve-se ao fato de ser dados de gastos em pesquisa totais para cada região e estado, não existindo valores específicos para o setor industrial e, consequentemente, para a indústria de transformação.

Nas duas outras equações, produto regional industrial e produto regional da indústria de transformação, não existem diferenças marcantes entre os dois modelos: efeito fixo e efeito aleatório. A única questão é que, enquanto no primeiro modelo a variável P\&D era não significativa apenas na equação do produto regional da indústria de transformação, no segundo modelo essa variável é não significativa nas regressões que têm como variáveis dependentes produto industrial e produto da indústria de transformação.

$\mathrm{Na}$ primeira equação, em que a variável dependente é o produto regional, todas as variáveis, com exceção de patentes, são significativas no nível de $1 \%$. No entanto, é a variável patente que apresenta maior influência sobre o produto regional. Entretanto, tanto a produtividade do trabalho quanto o consumo de energia elétrica industrial também exercem papel determinante no produto regional.

Os principais fatores a serem considerados em um processo de desenvolvimento das regiões brasileiras seriam patente, ou seja, a capacidade regional de criação/utilização de novas tecnologias; hiato da produtividade do trabalho; seguido pela imitação de novas tecnologias e pela difusão dessas novas tecnologias por todo o setor econômico, medido neste trabalho por meio do consumo de energia elétrica industrial.

Em relação à segunda equação, que tem como variável dependente o produto regional da indústria, apenas $\mathrm{P} \& \mathrm{D}$ apresenta-se não significativa. As demais variáveis são significativas a $1 \%$, sendo os coeficientes bastante próximos daqueles apresentados pelo modelo de efeitos fixos: produtividade, patente e consumo de energia elétrica industrial.

Os resultados apresentados pelo modelo de coeficientes aleatórios para a regressão em função do produto regional industrial são basicamente os mesmos daqueles observados no modelo de efeitos fixos, com a diferença que, nesse modelo de coeficientes aleatórios, a variável P\&D mostra-se não significativa para explicar o processo de crescimento regional de produto e renda. 
Tabela 3: Catching up: regiões brasileiras - dados anuais em painel 1990 a 2005, modelo de efeitos aleatórios

\begin{tabular}{lccc}
\hline & Produto Total & Indústria & Indústria de Transformação \\
\hline Constante & $9,08^{*}$ & $15,46^{*}$ & $14,36^{*}$ \\
\hline P\&D & $(28,71)$ & $(23,01)$ & $(16,95)$ \\
\hline Patente & $(9,41)$ & $0,02^{* * * *}$ & $0,02^{* * * *}$ \\
\hline Produtividade & $0,53^{* *}$ & $(0,69)$ & $0,69)$ \\
\hline & $(2,00)$ & $0,12^{*}$ & $(3,05)$ \\
\hline Energia Elétrica Industrial & $0,36^{*}$ & $(4,47)$ & $0,69 *$ \\
\hline & $(7,03)$ & $0,46^{*}$ & $(3,73)$ \\
\hline Número de observações & $0,30 *$ & $(3,13)$ & $0,14 *$ \\
\hline R $^{2}$ & $(11,20)$ & $0,08^{*}$ & $(3,43)$ \\
\hline Teste Chow & 175 & $(2,89)$ & 40 \\
\hline Teste LM & 0,97 & 40 & 14,70 \\
\hline Teste Hausman & 61,62 & 0,80 & 10,67 \\
\hline DW & 5,36 & 25,92 & 16,03 \\
\hline Teste Bartlet & 32,73 & 6,75 & 1,47 \\
\hline Os valos & 1,84 & 15,43 & 85,66 \\
\hline
\end{tabular}

Os valores entre parênteses referem-se à estatística $t$ de student.

*Nivel de significância 1\% **Nível de significância 5\% ***Nível de significância 10\%****Não significativo

Fonte: Cálculos do autor.

A terceira equação estimada com o produto regional de indústria de transformação como variável dependente, a exemplo da anterior, apresenta todas as variáveis significativas a $1 \%$, com exceção de P\&D. Também nesse caso os resultados dos modelos de efeitos fixos e de efeitos aleatórios são bastante próximos, sendo produtividade o fator que maior influência exerce sobre o produto. A seguir, aparece o consumo de energia elétrica industrial e patente.

Sendo as regressões resultantes dos dois modelos, coeficientes fixos e aleatórios, bastante similares, confirmam-se os resultados apresentados, que, dentre os fatores estudados, os mais importantes em um processo de crescimento do produto e renda da indústria de transformação regional são a endogeneização e a difusão das novas tecnologias nas máquinas e equipamentos (consumo de energia elétrica industrial), a imitação de novas tecnologias (produtividade do trabalho), e, por fim, o processo interno regional de inovação tecnológica (patentes). 
Dessa forma, pode-se dizer que, se as regiões menos desenvolvidas investirem em seu desenvolvimento tecnológico, isso resultará em crescimento do seu produto e renda. Por sua vez, se isso ocorrer a uma taxa superior à constatada nas regiões mais desenvolvidas, será verificada uma redução do gap entre essas regiões, ou seja, ocorrerá o catching up regional. Contrariamente, se as regiões mais desenvolvidas apresentarem relativamente maiores investimentos em desenvolvimento tecnológico, apresentarão maiores taxas de desenvolvimento econômico, resultando em uma elevação do gap entre as regiões.

\subsection{Estimação do modelo de efeitos fixos para os estados brasileiros}

O próximo passo foi estimar as mesmas equações apresentadas para todos os estados que compõem o território brasileiro. Os resultados são mostrados na tabela 4.

A primeira equação, que estima o produto estadual como variável dependente, apresenta todas as variáveis significativas a $1 \%$ e com os sinais

Tabela 4: Catching up - estados brasileiros - dados anuais em painel 1990 a 2005, modelo de efeitos fixos

\begin{tabular}{lccc}
\hline & Produto Total & Indústria & Indústria de Transformação \\
\hline Constante & $15,43^{*}$ & $14,35^{*}$ & $13,49^{*}$ \\
\hline P\&D & $(196,44)$ & $(41,70)$ & $(21,02)$ \\
\hline Patente & $(2,96)$ & $0,03^{*}$ & $0,01^{* * * *}$ \\
\hline Produtividade & $0,02^{*}$ & $(3,39)$ & $(0,71)$ \\
\hline & $(21,91)$ & $0,06^{*}$ & $0,04^{*}$ \\
\hline Energia Elétrica Industrial & $0,52^{*}$ & $(5,64)$ & $(2,43)$ \\
\hline & $(20,62)$ & $0,18^{*}$ & $0,30 *$ \\
\hline Número de observações & $0,02^{*}$ & $(3,63)$ & $(2,59)$ \\
\hline R2 & $(3,17)$ & $0,07^{*}$ & $(2,04)$ \\
\hline Teste Chow & 795 & $(2,79)$ & 185 \\
\hline Teste LM & 0,99 & 185 & 0,99 \\
\hline Teste Hausman & $2.047,73$ & 0,99 & 694,35 \\
\hline DW & 0,000000264 & 13,93 & 0,000000080 \\
\hline Teste Bartlet & 154,55 & 46,50 & 27,80 \\
\hline Os valores & 1,51 & 1,58 & 1,52 \\
\hline
\end{tabular}

Os valores entre parênteses referem-se à estatística $t$ de student.

*Nível de significância 1\%**Nível de significância 5\% *** Nível de significância 10\%****Não significativo.

Fonte: Cálculos do autor. 
esperados pela teoria. A variável com maior poder de influenciar o produto estadual é hiato da produtividade do trabalho, seguida pelas variáveis patente, consumo de energia elétrica industrial e P\&D.

Os resultados encontrados para os estados, em relação ao produto total, confirmam a importância da capacidade que cada estado apresenta de endogeneizar o desenvolvimento tecnológico para o processo de catching up. Além disso, novamente mostram que a variável hiato da produtividade do trabalho, ou a capacidade de imitação de tecnologias externas, é o fator com maior poder de influenciar um processo de crescimento econômico dos estados brasileiros. Confirmam, também, a importância da capacidade de geração interna de novas tecnologias, por meio tanto da variável patente quanto da variável P\&D.

Assim, em um processo de desenvolvimento que vise à eliminação das diferenças estaduais, ou seja, um processo de catching up entre os estados brasileiros, tanto a geração interna de inovações tecnológicas quanto a capacidade de apropriação mostram-se importantes.

De forma semelhante aos resultados verificados na primeira equação, quando se estima o produto estadual das indústrias como variável dependente, os coeficientes apresentam-se significativos a 1\%. Nessa equação, a influência da produtividade é menor, embora continue sendo a principal variável, e verifica-se uma elevação na importância das demais variáveis, consumo de energia elétrica industrial, patentes e P\&D.

Na terceira equação, quando se estima o produto estadual da indústria de transformação como variável dependente, a variável P\&D volta a ser não significativa e o consumo de energia elétrica industrial é significativo a 5\%, sendo as demais variáveis significativas a 1\%. A maior influência sobre o produto estadual da indústria de transformação é exercida pela produtividade do trabalho, seguida pelo consumo de energia elétrica industrial e patente.

Por sua vez, os resultados encontrados para a equação do produto industrial de transformação estimada com modelo de efeitos fixos dos estados confirmam aqueles encontrados no mesmo modelo estimado para as regiões. De novo percebe-se que os fatores com maior capacidade de influência sobre o crescimento do produto estadual são a apropriação de novas tecnologias e a criação de novas tecnologias. 


\subsection{Estimação do modelo de efeitos aleatórios para os estados brasileiros}

Por fim, procedeu-se à análise das regressões estimadas por meio do modelo de efeitos aleatórios, utilizando-se dados estaduais, como apresentado na tabela 5 .

$\mathrm{Na}$ equação que tem como variável dependente o produto estadual, todas as variáveis apresentam-se significativas a $1 \%$ e diretamente relacionadas com o produto, como era esperado. Novamente é a produtividade o fator que exerce a maior influência sobre a variável dependente, vindo, em seguida, o consumo de energia elétrica industrial, patentes e P\&D.

Os resultados apresentados pela regressão estimada por meio do modelo de coeficientes aleatórios para o produto total estadual confirmam aqueles apresentados pelo modelo de coeficientes fixos. Assim, pode-se afirmar que, em relação ao produto total, o crescimento do produto e da renda dos estados brasileiros mostra-se importante tanto quanto aos fatores ligados à ca-

Tabela 5: Catching up - estados brasileiros, dados anuais em painel 1990 a 2005, modelo de efeitos aleatórios

\begin{tabular}{lccc}
\hline & Produto Total & Indústria & Indústria de Transformação \\
\hline Constante & $14,90^{*}$ & $10,81^{*}$ & $10,13^{*}$ \\
\hline P\&D & $(34,43)$ & $(10,81)$ & $(8,54)$ \\
\hline Patente & $(2,43)$ & $0,09^{*}$ & $0,04^{*}$ \\
\hline Produtividade & $0,02^{*}$ & $(3,63)$ & $(1,61)$ \\
\hline & $(5,00)$ & $0,07^{*}$ & $0,05^{*}$ \\
\hline Energia Elétrica Industrial & $0,54^{*}$ & $(3,10)$ & $(5,01)$ \\
\hline & $(12,20)$ & $0,65^{*}$ & $0,70 *$ \\
\hline Número de observações & $0,04^{*}$ & $(4,47)$ & $(4,65)$ \\
\hline R $^{2}$ & $(3,90)$ & $0,35^{*}$ & $0,40 *$ \\
\hline Teste Chow & 795 & $(5,32)$ & 185 \\
\hline Teste LM & 0,48 & 185 & 0,59 \\
\hline Teste Hausman & $1.509,34$ & 0,70 & 356,26 \\
\hline DW & 89,72 & 258,94 & 103,82 \\
\hline Teste Bartlet & 154,55 & 97,28 & 27,80 \\
\hline Os & 1,50 & 46,50 & 1,56 \\
\hline
\end{tabular}

Os valores entre parênteses referem-se à estatística $t$ de student.

*Nível de significância 1\% **Nível de significância 5\%.

Fonte: Cálculos do autor. 
pacidade de cada estado de criar internamente novas tecnologias, como quanto à capacidade de imitação e difusão dessas novas tecnologias criadas.

Na segunda equação, que tem o produto industrial estadual como variável dependente, novamente todas as variáveis são significativas a $1 \%$ e com o sinal previsto pela teoria. Embora a produtividade continue como a variável com maior poder de influência sobre o produto industrial estadual, verifica-se uma elevação no poder de influência das demais variáveis.

Dessa forma, a exemplo do produto total estadual, os resultados da equação para o produto industrial estadual, no modelo de coeficientes aleatórios, confirmam aqueles encontrados na regressão estimada pelo modelo de coeficientes fixos. Tanto o processo de geração interna de novas tecnologias quanto a sua absorção pelo setor industrial são importantes na determinação do produto, ou seja, do desenvolvimento dos estados brasileiros.

Por fim, a última equação estimada tem como variável dependente o produto estadual da indústria de transformação. Nesse caso, a variável P\&D é significativa somente a $10 \%$, enquanto as demais o são a $1 \%$. Os resultados são bem próximos dos encontrados na equação anterior, sendo o coeficiente da produtividade igual a 0,70 , consumo de energia elétrica industrial igual a 0,40 , patente igual a 0,05 e P\&D igual a 0,04 .

A equação estimada para o produto da indústria de transformação estadual também mostra que, segundo o modelo de coeficientes aleatórios, para estimular o desenvolvimento da indústria de transformação dos estados brasileiros, devem-se incentivar tanto o desenvolvimento tecnológico interno, com a criação de novas tecnologias (patentes e P\&D), quanto a endogeneização das novas tecnologias, ou seja, a sua utilização pela indústria de transformação, seja por meio de novas máquinas e equipamentos (consumo de energia elétrica industrial), seja por meio da qualificação da mão de obra (produtividade do trabalho).

Acredita-se ser o desenvolvimento econômico função do desenvolvimento tecnológico, o que faz com que seja crucial, em primeiro lugar, estimular o desenvolvimento tecnológico de cada região e estado, seja na geração interna de novas tecnologias, pela imitação de tecnologias geradas externamente, ou ainda pela sua apropriação e difusão pelo setor produtivo. 


\section{CONCLUSÕES}

O Brasil é um país que, historicamente, tem como uma das principais características o desequilíbrio econômico entre as cinco grandes regiões - Norte, Nordeste, Sudeste, Sul e Centro-Oeste. Procurou-se mostrar, ao longo deste trabalho, a possibilidade de ocorrência de um processo de catching up, ou seja, a possibilidade de as regiões e estados menos desenvolvidos alcançarem aqueles mais desenvolvidos, em termos dos produtos total, industrial e da indústria de transformação.

Em primeiro lugar, pode-se concluir que a variável com maior poder de influência sobre o produto, o produto industrial e o produto da indústria de transformação, tanto em nível regional quanto em estadual, é a produtividade relativa, ou seja, a capacidade de as regiões e estados absorverem as inovações. Essa variável é importante para mostrar que a utilização ou não de novas tecnologias pode ser crucial para o desenvolvimento de dada região.

A variável patente, utilizada como proxy da capacidade de as regiões e estados desenvolverem novas tecnologias, também se mostrou significativa em todas as equações estimadas, embora tenha um menor impacto sobre o produto das regiões e estados. Dessa forma, pode-se inferir a importância de um processo de criação interna de tecnologia para o desenvolvimento futuro das regiões.

O consumo de energia elétrica foi utilizado como proxy da endogeneização das inovações por meio da formação bruta de capital fixo, ou seja, do investimento em novas máquinas e equipamentos. Os resultados obtidos para essa variável permitem concluir que a adoção de novas tecnologias incorporadas em máquinas e equipamentos exerce influência considerável sobre o produto da indústria e da indústria de transformação de uma dada região, mas não sobre o produto total, pois o consumo de energia elétrica pelas indústrias, por si só, não teria influência significativa sobre todo o setor produtivo.

Finalmente, a variável que apresentou maior divergência em relação à teoria foi $\mathrm{P} \& \mathrm{D}$, que representa, junto com patentes, a capacidade de uma dada região criar internamente tecnologias. Enquanto patente é a tecnologia já pronta para uso, P\&D é ainda o desenvolvimento tecnológico, e, assim, os resultados encontrados levaram à percepção de que existe um descom- 
passo entre o processo de criação de novas tecnologias e sua utilização, ou seja, que muitas inovações são criadas, mas não utilizadas.

Um resultado pode ser destacado. Analisando as estatísticas descritivas, observa-se que as regiões Norte e Nordeste apresentaram elevados valores para a média e a tendência da variável produtividade relativa. Posteriormente, analisando as equações estimadas, pôde-se identificar que essa mesma variável apresentou significativa influência sobre o crescimento do produto, produto industrial e produto da indústria de transformação. Isso indica que, embora as regiões menos desenvolvidas não venham realizando um esforço de desenvolvimento tecnológico, elas conseguem equiparar sua produtividade relativa àquela existente na região Sudeste. Acredita-se, assim, ser possível a existência de um processo de catching up, por meio de um processo de imitação tecnológica. Entretanto, acredita-se também ser extremamente importante que as regiões Norte, Nordeste e Centro-Oeste iniciem suas próprias pesquisas, almejando o desenvolvimento tecnológico e econômico.

Por fim, um resultado que é particularmente favorável à existência de um provável processo de cathing up. Por um lado, a variável produtividade é, geralmente, aquela com maior influência sobre o crescimento do produto, produto industrial e produto da indústria de transformação. Por outro lado, essa variável apresenta, nas regiões Norte e Nordeste, as estatísticas - médias e tendência - com valores bastante próximos ou até mesmo superiores aos apresentados pela região Sudeste. Esses resultados indicam que, embora as regiões menos desenvolvidas não estejam acompanhando os processos de desenvolvimentos de novas tecnologias desenvolvidos no Sudeste e Sul, estão utilizando essas tecnologias, o que se traduz em elevação da produtividade relativa. Dessa forma, acredita-se existir um caminho para ser seguido, na tentativa de minorar os desequilíbrios regionais. Entretanto, acredita-se também ser extremamente importante que as regiões Norte, Nordeste e Centro-Oeste iniciem suas próprias pesquisas, almejando o desenvolvimento tecnológico e econômico.

Dessa forma, pode-se dizer que uma maneira de as regiões e estados menos desenvolvidos (Norte, Nordeste, Centro-Oeste) conseguirem alcançar aqueles mais avançados (Sul e Sudeste), ou seja, realizarem o catching up, seria mediante um esforço de desenvolvimento tecnológico de cada região e estado que fosse superior àquele empreendido pela região e estado mais desenvolvido. 
O desenvolvimento tecnológico das regiões é uma consequência, podendo ser desenvolvidas novas tecnologias, aperfeiçoadas e adaptadas às tecnologias já existentes, aos recursos produtivos físicos e humanos de cada região. Dessa forma, as regiões serão capazes de usufruir dos novos padrões tecnológicos, sendo o desenvolvimento econômico um processo consequente, autossustentado, gerando um ciclo virtuoso na economia brasileira.

\section{REFERÊNCIAS BIBLIOGRÁFICAS}

ANDRADE, T. A. As desigualdades inter-regionais de desenvolvimento econômico no Brasil. Texto para Discussão, Brasília: IPEA, n. 156, out. 1988.

ASHEIM, B. T.; COENEN, L. The role of regional innovation systems in a globalising economy: comparing knowledge bases and institutional frameworks of Nordic clusters. Berlin: Conference 'Regionalization on Innovation Policy — Options and Experiences' organized by the German Institute for Economic Research, jun. 4-5, 2004.

BONELLI, R.; SILVA, J. C. F. da Crescimento industrial, ajuste estrutural e exportações de manufaturados: notas para a definição de uma estratégia de longo-prazo para a economia Brasileira. Texto para Discussão, Rio de Janeiro: IPEA, n. 69, nov. 1984.

BRAGA, H. C.; MATESCO, V. R. Progresso técnico na indústria Brasileira: indicadores e análise de seus fatores determinantes. Texto para Discussão, Rio de Janeiro: IPEA, n. 99, fev. 1986.

CANO, W. Ensaios sobre a formação econômica regional do Brasil. Campinas: Unicamp, 2002.

Raízes da concentração industrial em São Paulo. Campinas: Unicamp, 1998.

CASTRO, A. B. de. 7 Ensaios sobre a economia Brasileira, v. I e II. Rio de Janeiro: Forense Universitária, 1988.

COOKE, P. Regional innovation systems, asymmetric knowledge and the legacies of learning. In: RUTTEN, R.; BOEKEMA, F.; HOSPERS, G. (Eds.). The learning region: foundations, state of the art, future. Cheltenham: Edward Elgar - www.business.aau.dk/ike/upcoming/ Cooke.pdf. Capturado fev. 2006.

DINIZ, C. C. Globalização, escalas territoriais e política tecnológica regionalizada no Brasil. Texto para Discussão, Belo Horizonte: Cedeplar, n. 168, 34 p., 2001.

. Dinâmica regional recente da economia Brasileira e suas perspectivas. Texto para Discussão, Rio de Janeiro: IPEA, n. 375, jun. 1995.

; FERREIRA, A. H. B. Convergência entre as rendas per capita estaduais no Brasil. Texto para Discussão, Belo Horizonte: Cedeplar, n. 79, 19 p., 1994.

; CROCCO, M. Reestruturação econômica e impacto regional: o novo mapa da indústria Brasileira. In: Nova Economia, Departamento de Economia, Universidade Federal de Minas Gerais, v. 6, n. 1, p. 77-103, jul. 1996.

DOLOREUX, D.; PARTO, S. Regional innovation systems: a critical review - Unu - Intech Discussion Paper's - Issn 1564-8370 - www.urenio.org/metaforesight/library/17.pdf capturado nov. 2005. 
FAGERBERG, J. Why Growth Rates Differ. In: DOSSI, G.; FREEMAN, C.; NELSON, R.; SILVERBERG, G.; SOETE, L. (Eds.). Technical change and economic theory. Londres: Pinter Publishers, 1988.

FERNANDES, A. S. Reflexões sobre a abordagem de sistema de inovações - www.br.geocities. com/adsbicca/textos/siinter.pdf - capturado nov. 2005.

FREEMAN, C.; PEREZ, C. Structural crises of adjustment, business Cycle and investment behavior. In: DOSSI, G.; FREEMAN, C.; NELSON, R.; SILVERBERG, G.; SOETE, L. (Eds.) Technical change and economic theory. Londres: Pinter Publishers, 1988.

FURTADO, C. Formação econômica do Brasil. São Paulo: Companhia Editora Nacional, 2002.

GONÇALVES, E. A distribuição espacial da atividade inovadora Brasileira: uma análise exploratória. Texto para Discussão, Belo Horizonte: Cedeplar, n. 246, fev. 2005.

LEMOS, M. B.; CHEIN, F.; ASSUNÇÃO, J. J. Desenvolvimento desigual: evidências para o Brasil - www.anpec.org.br/encontro2005/artigos - capturado fev. 2006.

- CAMPOS, B.; BIAZI, E.; SANTOS, F. Capacitação tecnológica e catching up: o caso das regiões metropolitanas emergentes. Revista de Economia Política, v. 26, n. 1, p. 95-118, jan./mar. 2006.

LUNDVALL, B.-A. (Ed.) National systems of innovation. [S.1.]: Pinter, 1992.

MYTELKA, L. Local systems of innovation in a globalized world economy. In: Industry and Innovation, v. 7, n. 1, p. 15-32, jun. 2000.

NASSER, B. Economia regional, desigualdade regional no Brasil e o estudo dos eixos nacionais de integração e desenvolvimento. Rio de Janeiro. Revista do BNDES, v. 7, n. 14, p. 145-178, dez. 2000.

PACHECO, C. A. Novos padrões de localização industrial? Texto para Discussão, Brasília: IPEA, n. 633, mar. 1999.

PIMENTEL, E. A.; HADDAD, E. A. Desigualdades regionais no Brasil e sua dinâmica durante a década de 1990: um estudo especializado. (Monografia) - São Paulo: USP/Faculdade de Economia, Administração e Contabilidade - Departamento de Economia, 2004.

PRADO JR., C. História Econômica do Brasil. São Paulo: Brasiliense, 1987.

ROCHA, S. Desigualdade regional e pobreza no Brasil: a evolução - 1981/95. Texto para Discussão, Rio de Janeiro: IPEA, n. 567, jun. 1998.

SAVIOTTI, P. P. Crescimento da variedade: implicações de política para os países em desenvolvimento. In: LASTRES, H. M. M.; CASSIOLATO, J. E.; ARROIO, A. Conhecimento, sistemas de inovação e desenvolvimento. Rio de Janeiro: UFRJ, Contraponto, 2005.

SIQUEIRA, T. V. DE; SIFFERT FILHO, N. F. Desenvolvimento regional no Brasil: tendências e novas perspectivas. Revista do BNDES, Rio de Janeiro, v. 6, n. 16, p. 79-118, dez. 2001.

TAVARES, M. da C. Da substituição de importações ao capitalismo financeiro. Rio de Janeiro: Zahar Editores, 1983.

WINTER, S.; NELSON, R. R. An evolutionary theory of economic change - the Belknap Press. [S.1.]: Harvard University Press, 1982. 